\title{
Longitudinal Relations Among Parental Emotional Expressivity, Children's Regulation, and Quality of Socioemotional Functioning
}

\author{
Nancy Eisenberg, Carlos Valiente, Amanda Sheffield Morris, Richard A. Fabes, Amanda Cumberland, \\ Mark Reiser, Elizabeth Thompson Gershoff, Stephanie A. Shepard, and Sandra Losoya \\ Arizona State University
}

\begin{abstract}
The role of regulation as a mediator of the relations between maternal emotional expressivity and children's adjustment and social competence was examined when children $(N=208)$ were 4.5 to just 8 years old (Time 1, T1) and 2 years later (Time 2, T2). At T2, as at T1, regulation mediated the relation between positive maternal emotional expressivity and children's functioning. When T1 relations and the stability of variables over time were controlled for in a structural equation model, T2 relations generally were nonsignificant, although parents' dominant negative expressivity predicted high regulation. In contrast, in regressions, the findings for parent positive expressivity, but not negative expressivity, held at T2 when T1 variables were controlled. Thus, relations for negative expressivity, but not positive expressivity, changed with age.
\end{abstract}

In the last two decades, a number of developmental theorists have argued that an essential component of children's adjustment is learning how to regulate emotional responses and related behaviors in socially appropriate and adaptive ways (Bridges \& Grolnick, 1995; Cicchetti, Ackerman, \& Izard, 1995; Kopp, 1982; Saarni, 1990). Yet until recently, there has been little research on the influence of the family context in the development of children's emotion regulation abilities, especially past infancy. Moreover, despite Rothbart and Bates's (1998) discussion of the importance of examining the mediational and moderational processes involved in the relations among temperament (including emotionality and regulation), parenting, and children's socioemotional outcomes, few researchers have done so. The purpose of the

Nancy Eisenberg, Amanda Sheffield Morris, Amanda Cumberland, Elizabeth Thompson Gershoff, Stephanie A. Shepard, and Sandra Losoya, Department of Psychology, Arizona State University; Carlos Valiente and Richard A. Fabes, Department of Family and Human Development, Arizona State University; Mark Reiser, Department of Economics, Arizona State University.

Amanda Sheffield Morris is now at the Department of Psychology, University of New Orleans. Elizabeth Thompson Gershoff is now at the School of Public Health, Columbia University. Stephanie A. Shepard is now at the Counseling Department, University of Oregon.

This research was supported by Grants 1 R01 HH55052 and 1 R01 MH 60838 from the National Institutes of Mental Health (NIMH) and by NIMH Research Scientist Award K05 M801321 to Nancy Eisenberg.

We wish to thank the many students who assisted in this study; the parents and children involved; the principals and teachers in the Tempe, Kyrene, Mesa, Scottsdale, Gilbert, Chandler, Phoenix, Peoria, and Washington school districts (and other districts with few teachers); and especially the numerous teachers at the Myers, Hudson, Scales, Curry, Evans, and Holdeman schools. We would also like to thank Bridget A. Murphy and Ivanna K. Guthrie for their assistance in the data collection and the expert rates for their assistance.

Correspondence concerning this article should be addressed to Nancy Eisenberg, Department of Psychology, Arizona State University, Tempe, Arizona 85287-1104. E-mail: nancy.eisenberg@asu.edu present work was to address this gap in research on children's emotional development.

Although most developmentalists agree that parenting is linked to children's social and emotional development, the mechanisms that might be involved are less clear (Collins, Maccoby, Steinberg, Hetherington, \& Bornstein, 2000; Darling \& Steinberg, 1993). Gottman, Katz, and Hooven (1997) and Eisenberg, Cumberland, and Spinrad (1998) suggested that one way familial interactions affect children's adjustment is through their impact on children's emotion regulation. On the basis of this line of argument, we sought to examine the links between parenting and children's social competence and problem behaviors, and mediation of this relation by children's regulation. Moreover, we examined these relations using longitudinal data.

\section{Emotional Climate of the Family: Parenting and Family Emotional Expressiveness}

It is likely that the family is the primary context in which children first learn about how emotions are typically expressed, the messages they convey, and various ways to manage them (Denham, 1998; Dunn, Brown, \& Beardsall, 1991). Moreover, the emotional climate in the home likely affects children's emotional reactivity and the quality and security of relationships with other members of the family (e.g., Cummings \& Davies, 1996; Halberstadt, Crisp, \& Eaton, 1999).

The quality of the emotional climate in the home is due in part to parents' expression of emotion (Halberstadt et al., 1999). Parental emotional expressivity typically is measured in one of two ways (Halberstadt et al., 1999): (a) as parents' expression of positive and negative emotion when interacting with the child or (b) as parents' general tendencies to express emotion in interactions in the family. The latter can be viewed as an index of family (or parental) expressiveness or "the predominant style of exhibiting nonverbal and verbal expressions within a family" (Halberstadt, Cassidy, Stifter, Parke, \& Fox, 1995, p. 93). Parental emotional expressivity defined in this manner includes parental 
expression of emotion not directed at a given child and frequently is assessed with parent-report measures (e.g., Bronstein, Fitzgerald, Briones, Pieniadz, \& D’Ari, 1993; Halberstadt, 1986). Parents' reports on this construct have been substantially correlated with measures of emotional expressiveness but are more modestly and less consistently related to self-reported experience of negative emotion (e.g., anxiety, depression) and do not correlate with social desirability (Halberstadt et al., 1995). Parental emotional expressivity directed toward a specific child has often been assessed with observations as well as with parental self-reports. Parental expressivity generally is viewed as a component of parenting style (behaviors that create an emotional climate) rather than as a specific parenting practice that reflects beliefs, goals, or values related to a specific domain of behavior (see Darling \& Steinberg, 1993). However, parental expression of emotion may have specific effects on children in addition to creating an atmosphere that is expected to moderate the relation between specific practices and developmental outcomes in children (Darling \& Steinberg, 1993; Hoffman, 1983).

There is considerable evidence that parents' expression of emotion is related to their children's socioemotional competence. Parents who are high in warmth and positive emotion, and low in the expression of disapproval, hostility, and other negative emotions directed toward their children, tend to have socially competent, adjusted children who are also skilled in social understanding (Lindahl, 1998; Matthews, Woodall, Kenyon, \& Jacob, 1996; Rothbaum \& Weisz, 1994; Rubin, Hastings, Chen, Stewart, \& McNichol, 1998; Scaramella, Conger, \& Simons, 1999). In addition, both parental and family expressiveness, especially positive expressivity, have been associated with children's social competence, emotional understanding, positive emotionality, prosocial behavior, and self-esteem (Boyum \& Parke, 1995; Bronstein et al., 1993; Cassidy, Parke, Butkovsky, \& Braungart, 1992; Halberstadt et al., 1999).

Findings for negative parental emotional expressivity are more complex, and those for parental negative expressivity in general (i.e., not necessarily directed at the child) are sparse (Halberstadt et al., 1999). Generally, parental negative expressivity or hostility directed at the child has been negatively related to toddlers' and children's socioemotional competence (Denham, 1989; Isley, O'Neil, Clatfelter, \& Parke, 1999) and positively related to problems with adjustment (e.g., MacKinnon-Lewis \& Lofquist, 1996; Messer \& Gross, 1995). In regard to general parental negative emotional expressivity, Denham et al. (2000) found that parentreported dispositional hostility was positively correlated with children's externalizing problems but usually did not predict externalizing problems 2 or 4 years later when parental anger during interactions and prior levels of externalizing problems were controlled. Contrary to the expected negative relation between parental negative expressivity and children's social competence and adjustment, parental expression of negative emotion in response to children's expression of anger and sadness has also been related to low levels of preschoolers' externalizing problems (Teti \& Cole, 1995). Further, parent-reported dominant (hostile or assertive) negative emotion in the family (as well as positive and negative expressivity combined) more generally has been related to higher levels of acceptance of teachers' authority (M. T. Greenberg, personal communication, July 2, 2001; data in Greenberg, Lengua,
Coie, \& Pinderhughes, 1999). Thus, there are inconsistencies in the findings for parental negative expressivity.

As suggested by Halberstadt et al. (1999), the relation between parental negative expressivity and children's adjustment may vary depending on the kind of family expressiveness and the measure of adjustment. Consistent with the notion that the type of negative emotion is critical is Eisenberg, Gershoff, et al.'s (2001) finding that mothers' confrontative negative expressivity, but not their expression of softer negative emotions, was related to externalizing problems and low social competence in elementary school children (also see Crockenberg, 1985; Eisenberg et al., 1991,1992). In addition, relatively high quantities of parental negative emotionality directed toward a child may be most related to negative developmental outcomes. Indeed, some investigators have argued that moderate exposure to negative emotion, especially expressed appropriately and not on an ongoing basis, is important for children to learn about emotions and how to regulate them (Hoffman, 2000; also see Dunn \& Brown, 1994).

\section{Processes Involved in the Relation of Parental Expressivity to Children's Social Functioning and Regulation}

There are a number of reasons to expect parents' emotions directed at the child or expressed in the family to be linked to children's adjustment and social competence. One set of explanations concerns the effects of parental expressivity on the quality of the relationship between a parent and a child. For example, when parents are warm and supportive rather than hostile with their children, children are likely to believe that their parents are concerned with their welfare and interests; consequently, such children are likely to be motivated by feelings of trust and reciprocity (Dix, 1991,1992) and to comply with and internalize supportive parents' standards for appropriate behavior, including demands for self-regulation (Grusec \& Goodnow, 1994; Parpal \& Maccoby, 1985). Moreover, parents who express positive emotions model positive ways of responding to others and to events in their lives, whereas parents who express negative emotions do not and may even model hostile, dysregulated approaches to dealing with emotions (Cole, Michel, \& Teti, 1994).

As already noted, a third related type of explanation pertains to the potential effects of parental expressivity on children's emotional arousal and emotion regulation. Children's regulatory capacities include the abilities to voluntarily focus attention, shift attention, and inhibit or initiate behavior; these temperamentally based behaviors can be used to modulate emotional reactivity to events as well as emotionally driven behavior (Derryberry \& Rothbart, 1997; Eisenberg, Fabes, Guthrie, \& Reiser, 2000; Rothbart, Ahadi, \& Hershey, 1994). Although temperamental individual differences, including children's regulatory abilities, are thought to derive partly from heredity and constitutional factors, experience is also believed to contribute to these differences (Rothbart \& Bates, 1998). Indeed, a number of theorists (Campos, Campos, \& Barrett, 1989; Thompson, 1994; Walden \& Smith, 1997) have argued that children's abilities to regulate their attention, emotion, and behavior are embedded in the context of social relationships and that children's self-regulation can be promoted by, and perhaps even partly learned from, their parents (Gottman et al., 1997; Kopp, 1982). Consistent with the latter argument are 
researchers' findings that children model adults' self-denial (Grusec, 1971) and can be taught attentional strategies of regulation (Mischel, Shoda, \& Rodriguez, 1989).

Both Eisenberg et al. (1998) and Gottman et al. (1997) have presented models in which children's regulatory capacities mediate the relation between parental emotion-related child-rearing practices or behaviors and children's social behavior and adjustment. There are numerous reasons to predict a mediated relation. Parents who are positive and supportive with their children may help them to manage their distress and cope successfully in stressful situations (Skinner \& Wellborn, 1994). In turn, this enhanced regulatory ability might foster the development of social skills and reduce negative expectations about social interactions (Dusek \& Danko, 1994; Hardy, Power, \& Jaedicke, 1993). Parental positive expressivity may also contribute to children's beliefs about how much and what types of emotional expressions are appropriate and effective in social interactions, and such knowledge may foster both self-regulation and social skills (Denham, Zoller, \& Couchoud, 1994; Eisenberg et al., 1998). Moreover, as suggested by Hoffman (1983, 2000), parents' hostile or punitive negative expressivity is likely to produce overarousal in their children, which could undercut regulation and learning in the specific context. In contrast, if parents are positive with their children in stressful situations, children may be better able, and more motivated, to process parents' messages and other relevant information and thus be more likely than overaroused children to learn appropriate strategies for handling their emotions and emotionally driven behavior.

There is some evidence, albeit limited, that children's regulation mediates the relation between parental expressivity and children's social competence and problem behavior, although the findings are not entirely consistent. Empirical support for the association between parental expressivity and children's social competence and problem behavior has already been discussed. In regard to the link between parental expressivity and children's regulation, researchers have found an association between maternal responsivity to infants' emotional cues and infants' use of self-regulatory behaviors (Cohn \& Tronick, 1983; Gable \& Isabella, 1992). Moreover, mothers' reported positive expressivity in the family was related to higher levels of toddlers' self-soothing behavior, whereas motherreported sadness was inversely related (Garner, 1995; see Garner \& Power, 1996, for more mixed findings). In older children, maternal acceptance and support were linked to successful coping (Hardy et al., 1993; Kliewer, Fearnow, \& Miller, 1996), and college students and adults from negatively expressive families reported less control than their peers over feelings of anger even when researchers controlled for the intensity of the anger (Burrowes \& Halberstadt, 1987).

If emotion-related regulation mediates the relation of parental expressivity to children's socioemotional competence, one generally would expect a relation between children's regulation and their social competence and adjustment. Numerous researchers have found that externalizing problems are associated with low effortful attentional and behavioral regulation and impulsivity (Eisenberg, Cumberland, et al., 2001; Huey \& Weisz, 1997; Lengua, West, \& Sandler, 1998; Pulkkinen, 1986; Zahn-Waxler, Schmitz, Fulker, Robinson, \& Emde, 1996). Moreover, differences in children's regulation predict differences in their social compe- tence, empathy, and conscience (Eisenberg et al., 2000; Kochanska, Murray, \& Coy, 1997; Rothbart et al., 1994).

Findings regarding the relation of internalizing problems to regulation have been less consistent than those for externalizing problem behaviors. Eisenberg, Cumberland, et al. (2001) found that internalizing children were low in attentional regulation, similar to nondisordered children in effortful inhibitory control, and high in involuntary inhibition of behavior (i.e., low in impulsivity; also see Huey \& Weiss, 1997). Lengua et al. (1998) found a negative relation between children's attentional focusing and depression in the correlational analyses but generally not in structural equation modeling (when other variables were controlled). Moreover, Zahn-Waxler et al. (1996) obtained no relation between internalization of control (e.g., good impulse control, capacity to attend and focus) and level of anxiety (an aspect of internalizing). Thus, it is unclear if internalizing problems are related to low effortful regulation (e.g., the ability to shift or focus attention or to inhibit behavior as needed), although they likely are consistently associated with low impulsivity (Eisenberg, Cumberland, et al., 2001).

Only a few investigators have explicitly examined regulation as a mediator between emotion-related parenting and child outcomes. Brody and Ge (2001) assessed parental nurturance/support versus negativity - a construct that likely included more than just parental emotional expressivity - and found that supportive parenting predicted children's self-control at two points in time; children's self-control, in turn, was negatively related to children's problems with adjustment (hostility, depression, and low self-esteem). The data did not support the possibility that children's self-regulation predicted later parenting. Although they did not assess family expressivity per se, Gottman and colleagues (1997) found that parents who were supportive in regard to encouraging the appropriate expression of emotion and coaching children about their emotions had children who were relatively high in regulation. Gottman et al. did not, however, find a relation between children's regulation and either parental derogatory behavior or parental scaffolding or praising (at least when other variables were controlled in a structural model). Eisenberg et al. (1999) found that parents' reports of punitive reactions to children's negative emotions-which likely involved some negative emotion-were negatively related to children's regulation, with regulation and maternal punitive reactions predicting one another over time.

Eisenberg and colleagues (Eisenberg, Gershoff, et al., 2001; Eisenberg, Liew, \& Pidada, 2001) specifically examined the mediating role of children's effortful regulation in the relation of parental emotional expressivity to children's social competence and adjustment. In the United States and Indonesia, they found that parental negative expressivity (but only dominant negative expressivity in the United States) was related to low regulation in children, which in turn was related to externalizing problems and low social competence. In the United States, the negative relation between children's regulation and internalizing problems was significant and there was no mediated effect between maternal emotional expressivity and internalizing problems through children's regulation (internalizing behavior was not assessed in Indonesia). In the United States, but not in Indonesia, regulation mediated the relation between parental positive expressivity and children's social competence and low externalizing behavior. Structural equation models with the U.S. sample suggested that the direction of 
the effects was more likely from parenting to child outcomes than the reverse. However, in both samples, the data were concurrent rather than longitudinal, so it was difficult to make any causal inferences.

\section{The Present Study}

The purposes of the present study were twofold: (a) to replicate the findings obtained in Eisenberg, Gershoff, et al. (2001) using the same children 2 years later (Time 2, or T2) and (b) to determine if any relations were due to the stability of those relations obtained 2 years previously (Time 1, or T1) or to a change in regulation (due to maternal expressivity) over the 2 years. We predicted that the same pattern of relations would be obtained, but we were not sure if the pattern would support the conclusion that $\mathrm{T} 2$ parenting had effects on $\mathrm{T} 2$ social competence and adjustment beyond those that were due to consistency of the variables from T1 to T2. It seemed quite possible that the relations among parenting, children's regulation, and children's social competence and adjustment would be well established at T1 and that relations among them at an older age would be due primarily to stability over time in parenting and children's regulation, social competence, and adjustment. Structural equation modeling (SEM) was used to examine the aforementioned relations. Although SEM cannot prove causality, it can be used to test the plausibility of causal associations, especially when the data are longitudinal.

In the past, considerable concern has been expressed regarding the confounding of measures of temperament and adjustment (Bates, 1990; Sanson, Prior, \& Kyrios, 1990). Empirical findings indicate that such confounding of items is a greater problem for internalizing than for externalizing problem behaviors (Sanson et al., 1990). Moreover, Lengua et al. (1998) generally found similar patterns of findings when they used confounded and adjusted (unconfounded) measures in analyses of the relations between temperament (including regulation) and adjustment. Nonetheless, on the basis of expert ratings, we removed the items that differentiated least clearly between temperamental regulation and children's adjustment in an attempt to minimize any possible confounding of measures.

Finally, we examined whether sex, age, and socioeconomic status (SES) moderated the pattern of relations. The relation of family or parental expressiveness to child outcomes often varies with the sex of the child and the dependent measure (e.g., Boyum \& Parke, 1995; Bronstein et al., 1993; Eisenberg et al., 1992). However, sex did not moderate the pattern of results at T1, so moderation was not expected at $\mathrm{T} 2$. Although regulation does change in the school years (Murphy, Eisenberg, Fabes, Shepard, \& Guthrie, 1999; Williams, Ponesse, Schachar, Logan, \& Tannock, 1999), we did not have any clear reason to expect the relations of interest to vary in strength for children in early and later elementary school, and no moderation was found for age at T1. SES was examined as a moderator because it sometimes is related to parenting behavior (Parke \& Buriel, 1998), but as at T1 (Eisenberg, Gershoff, et al., 2001), it was not expected to affect the pattern of relations. This expectation was bolstered by the fact that relations among socialization, regulation, and social functioning or emotional understanding in children from lower SES samples and/or minority samples generally have been similar to those found in children from higher SES and/or European American samples (Smith, 2001; Smith \& Walden, 2001).

\section{Method}

\section{Participants}

Participants were part of an ongoing longitudinal study of children's socioemotional development (Eisenberg, Cumberland, et al., 2001; Eisenberg, Gershoff, et al., 2001; Spinrad et al., 1999). Children were recruited primarily through local schools but also through newspaper ads and flyers that were placed at preschools and elementary schools. Because a goal of the study was to obtain a diverse sample with respect to problem behaviors, the Child Behavior Checklist (CBCL; Achenbach, 1991a) was administered over the phone to a parent, usually the mother. ${ }^{1}$ Parents of 315 children completed the CBCL; all children who had $T$ scores of 60 or higher on either the Externalizing or Internalizing scales were chosen to participate (scores of 60 to 63 are viewed as indicating moderate risk for clinical problems; Achenbach, 1991b, p. 63). For purposes of matching, a child with $T$ scores of 60 or higher on both the Internalizing and Externalizing scales was considered either an internalizer or an externalizer depending on which score was higher. Children with $T$ scores below 60 on both the Externalizing and Internalizing scales were considered control children. To equate children with and without problem behaviors on demographic variables, we matched problem children (considering them as either externalizers or internalizers on the basis of which score was higher) with nonproblem children of the same sex, age, race (when possible), and social class (on the basis of parents' reports of education and occupation). Not all children selected attended the experimental session, and sometimes matching on all variables was impossible, which resulted in approximate matching (see Eisenberg, Gershoff, et al., 2001; Spinrad et al., 1999). It is important to note that children with scores below 60, scores of 60 , and scores above 60 were included so that the range of scores was continuous rather than strictly bimodal.

The above procedures resulted in the recruitment of 214 children (96 girls and 118 boys; mean age $=73$ months, $S D=9.59$ months) and at least one of each child's parents (henceforth called the T1 sample). Participants were primarily from European American working- and middle-class families (see Eisenberg, Gershoff, et al., 2001). At T1, 12 families were excluded from the analyses because only fathers from those families came into the laboratory; this resulted in a total of 202 families.

Approximately 2 years later (henceforth called T2), families were recontacted and asked to participate in the follow-up study. Twenty-nine families of the total 214 families from T1 did not participate at T2 (although 8 of these 29 were mothers who completed the measure of problem behavior on the phone), resulting in a sample of 185 families at T2. In addition to the 29 families who dropped from the sample, 8 families were not included at $\mathrm{T} 2$ because only fathers in those families completed the parent questionnaires, which resulted in an $N$ of 177 for the reported variables. Ten of these families did not come into the laboratory (most had moved away), but questionnaire measures were available for them. In addition, observational data from 5 of the 167 families with these data at

${ }^{1}$ T. M. Achenbach (personal communication, January 16, 2001) compared CBCL and Youth Self-Report (YSR) scores for phone administration versus in-person administration in a national sample, as well as scores on the Young Adult Behavior Checklist and the Young Adult Self-Report administered by phone versus in person. Across the 45 separate analyses of problem scale scores, 7 showed significant $(p<.05)$ but very small differences, compared with 5 expected by chance at $p<.05$. After Bonferroni correction, none would be significant. There were no significant interactions between gender and phone versus in-person administration. 
T2 were not included because the father, not the mother, was present for the observation tasks. In summary, at T2 there were 177 children whose mothers completed the questionnaire data, 167 children who attended the laboratory session, and 162 mothers who completed the observational task. Because there were 202 families with data at T1 and an additional 6 families who had mother data at $\mathrm{T} 2$ but not $\mathrm{T} 1$, there were 208 families in the SEM analyses.

Four multivariate analyses of variance (MANOVAs; one each for mothers' reports at $\mathrm{T} 1$, teachers' reports at $\mathrm{T} 1$, the observed variables at $\mathrm{T} 1$, and children's gender and SES at T1) were computed to compare children with missing data (either because they did not attend the experimental session at $\mathrm{T} 2$ or because a reporter did not complete all the measures at $\mathrm{T} 2$ ) with children with complete data. None of the multivariate $F$ s was significant (and the only significant univariate $F$ was for observed negative expressivity, $p<.047$, which was higher for missing families). According to chi-square tests, neither child sex nor child ethnicity was related to attrition. $^{2}$

The 177 children at T2 (80 girls and 97 boys) were primarily from European American families (73\%); 4\% were American Indian, $4 \%$ were African American, $14 \%$ were Hispanic, $1 \%$ were Asian, and $4 \%$ were of other origins. Parents were moderately well educated, albeit quite diverse in this regard. Mean levels of education for mothers and fathers were 3.82 and 3.85 , respectively $(1=$ less than a high school education, $2 \%$ of mothers and $6 \%$ of fathers; $2=$ high school graduate, $13 \%$ of mothers and $19 \%$ of fathers; $3=$ some college, $38 \%$ of mothers and $19 \%$ of fathers; $4=$ 2-year college degree, $9 \%$ of mothers and $14 \%$ of fathers; $5=4$-year college degree, $24 \%$ of mothers and $21 \%$ of fathers; $6=$ professional degree, $14 \%$ of mothers and $21 \%$ of fathers). Annual family income ranged from less than $\$ 10,000$ to greater than $\$ 100,000$, with a mean and median of $\$ 40,000$

\section{Procedure}

In most cases, the children and their mothers came to a university laboratory at both time periods. Mothers completed a packet of questionnaires, including measures of their own expressiveness in the family and of their children's regulation, problem behaviors, and social competence. At both T1 and T2, children's regulation was observed while they completed a puzzle task. At T1, mothers' observed expressivity with their children was coded when they completed a puzzle task with their child. Mothers were allowed to help their child as much as necessary without actually doing the puzzle; children were told they would receive an attractive prize if they finished the puzzle (see Eisenberg, Gershoff, et al., 2001, for more detail). At T2, mothers' expressivity was observed early in the session while the mother and the child were left alone in the laboratory as well as when the experimenter attached electrodes to the child to collect physiological data. At both T1 and T2, after the laboratory session, children's teachers ( $N=180$ at T2) completed questionnaires assessing children's regulation, problem behaviors, and social competence (generally late in the same semester in which the child came to the laboratory).

\section{Measures}

Unless otherwise noted, the measures and data reduction at $\mathrm{T} 2$ were identical to those at $\mathrm{T} 1$, although potentially confounded items in the adjustment and temperament scales were dropped in the present study (see later section on Procedures for Removing Potentially Confounded Items) but not in the T1-only analyses reported in Eisenberg, Gershoff, et al. (2001).

\section{Mothers' Expressivity}

Mothers' reported expressivity. Mothers completed the SelfExpressiveness in the Family Questionnaire (SEFQ) at both T1 and T2
(Halberstadt et al., 1995). Mothers rated the items on a 9-point scale ranging from 1 (rarely expresses the emotion) to 9 (frequently expresses the emotion) to indicate the frequency with which they expressed a range of emotions in a variety of settings typical for most families. As at T1, the Positive emotional expressivity subscale was used as an index of mothers' expression of positive emotion (e.g., "Praising someone for good work" and "Telling a family member how happy you are"; 14 items; T1 $\alpha=.85$; $\mathrm{T} 2 \alpha=.86$ ). As at T1, the T2 Dominant Negative subscale was used as the index of mothers' self-reported negativity (e.g., "Showing contempt for another's action," "Showing dislike for someone"; 10 items; T1 $\alpha=.80$; T2 $\alpha=.78){ }^{3}$

Observed maternal emotion. At T1, mothers' observed emotion was coded while the mother and the child completed a mildly stressful puzzle task (the task lasted $5 \mathrm{~min}$ ). Mothers' positive and negative emotions (based on facial, bodily, vocal, and verbal cues) were coded every $30 \mathrm{~s}$ on a scale ranging from 1 (no positive or negative affect) to 5 (very frequent or intense positive or negative affect), resulting in 10 codes; mothers' global warmth also was coded once per interaction (on a 1 to 5 scale). Interrater reliabilities on these continuous scales for $25 \%$ of the interactions were $.82, .74$, and .65 for mothers' positive emotions, negative emotions, and global warmth, respectively. Because the positive affect and warmth measures were highly correlated, $r(197)=.66, p<.01$, they were combined to form a T1 composite of observed positive expressivity. T1 observed negative emotional expressivity was calculated as the mean of the 30 -s negative affect codes.

At T2, mothers' emotions were observed while an experimenter attached the physiological equipment to the child and during 2 min when the mother and the child were alone just prior to the hook-up (the T1 mother-child puzzle interaction was not done at T2). Only mothers' observed positive emotion was used in the current study because negative expressions of emotion occurred very infrequently during these tasks $(M=1.01$ for the hook-up procedure and 1.02 for the 2-min mother-child alone interaction-the scale ranged from 1 to 5). Only 2 mothers displayed some negative affect during the hook-up procedure, and only 8 mothers dis-

\footnotetext{
${ }^{2}$ According to primary parents' report of problem behaviors, at $\mathrm{T} 1$ there were 70 controls (e.g., children with $T$ scores below 60 on both the Externalizing and Internalizing scales), 30 children with $T$ scores above 60 on the Externalizing scale only, 33 children with $T$ scores above 60 on the Internalizing scale only, and 69 children who had $T$ scores above 60 on both the Externalizing and Internalizing scales. At T2, there were 77 controls, 21 children with $T$ scores above 60 on the Externalizing scale only, 30 with $T$ scores above 60 on the Internalizing scale only, and 49 who had $T$ scores above 60 on both the Externalizing and Internalizing scales. According to $t$ tests, children in the 29 families that had no data at T2, compared with those with at least some data at $\mathrm{T} 2$, were rated as less regulated at $\mathrm{T} 1$ by mothers, $t(208)=-2.07, p<.04$, and teachers, $t(193)=-2.14, p<.03$, and were less regulated during the observational puzzle task at $\mathrm{T} 1, t(210)=-3.20, p<.01$.

${ }^{3}$ Six positive expressivity items in the SEFQ that were not recommended for a short Positive expressivity scale by Halberstadt et al. (1995) were dropped to save administration time. In addition, the item "Sulking over unfair treatment by a family member," which was coded as submissive negative emotion in Halberstadt (1986) but as dominant negative emotion in Halberstadt et al. (1995), was left as submissive negative emotion. This decision was based on both face validity and the finding that dropping the item from the Negative Submissive scale lowered the alpha of that scale by .03 and only lowered the alpha for the Negative Dominance scale by .01. The Negative Dominance scale without this item correlated .99 with the scale with this item, so it made little difference in the findings. Submissive negative emotion was not used in the main analyses because it has been less clearly linked to developmental outcomes and generally was weakly related to children's social competence and adjustment at T1.
} 
played some negative affect during the 2-min time alone with the child. However, considerable maternal expression of positive emotion was observed. During the physiological hook-up procedure, mothers' overall positive affect $(M=4.11)$ and support/warmth $(M=4.07)$ were coded on a scale ranging from 1 (low positive affect or support) to 5 (high positive affect or support) (interrater $r$ s, based on independent codes for 47 participants, were .87 and .85 ). Warmth included displays of closeness, friendliness, encouragement, smiling at the child, and physical affection. Because the two ratings were highly related, $r(159)=.72, p<.01$, they were averaged to form a T2 observed hook-up positive expressivity composite. During the mother-child 2-min interaction, mothers' positive emotion (coded every $30 \mathrm{~s}$ for $2 \mathrm{~min} ; M=1.82$ ) and overall warmth (scored once; $M=4.40$ ) were coded on 1 to 5 scales from the videotapes. The interrater reliability (Pearson $r$ ) for 47 participants was .85 for the mean of the positive affect codes and .64 for warmth. Warmth and positive affect were substantially related, $r(160)=.49, p<.01$, and were averaged to form a composite measure of $\mathrm{T} 2$ observed positive expressivity during the mother-child interaction.

\section{Procedures for Removing Potentially Confounded Items}

Unlike in the initial T1 analyses (Eisenberg, Gershoff, et al., 2001), the adult-reported regulation and problem behavior scales were modified to deal with potential overlap of items between the two types of scales. Using rating procedures similar to Lengua et al. (1998), 32 experts in the field (24 faculty; 8 graduate students) of temperament and/or child psychopathology rated temperament items from the Children's Behavior Questionnaire (CBQ; Rothbart, Ahadi, Hershey, \& Fisher, 2001) reflecting attention shifting, attention focusing, inhibitory control, sadness, fear (parent only), and anger and rated child psychopathology items reflecting externalizing (aggression and delinquency) and internalizing (withdrawn, anxious/depressed, and somatic complaint) items from the CBCL (Achenbach, 1991a, 1991b). Each expert completed a questionnaire measure that assessed how much each item reflected either temperament or behavior problems $(1=\mathrm{a}$ much better measure of temperament than of symptoms; $3=$ not a better measure of either temperament or symptoms; substantial content for both; $5=$ a much better measure of symptoms than temperament). The means of the experts' ratings for each item were calculated. Items that experts rated as a better measure of the construct not intended to be measured (e.g., when an item designed to measure temperament was rated as a better measure of problem behavior) were considered to be contaminated. Thus, temperament items that received mean scores greater than 3.00 and symptom items that received mean scores less than 3.00 were removed from the corresponding scales. Specific items dropped are discussed in the sections on each measure.

\section{Children's Regulation}

Reported regulation. The CBQ (Rothbart et al., 2001) was completed by mothers and teachers at $\mathrm{T} 1$ and $\mathrm{T} 2$. This measure was designed for parental reports, so some items were modified slightly (or dropped) for teachers. The Attention Focusing (e.g., "When drawing or coloring in a book, shows strong concentration"; 9 items), Attention Shifting (e.g., "Can easily shift from one activity to another"; 11 items), and Inhibitory Control (e.g., "Can lower his/her voice when asked to do so"; 13 items) subscales were used to assess children's regulation. On the basis of the expert ratings, 2 out of 11 items for both parents and teachers were deleted for the Attention Shifting subscale ("Sometimes has a dreamy quality when others talk to her/him, as if she/he were somewhere else" and "Sometimes doesn't seem to hear me when I talk to her/him."). There were no contaminated items for the Attention Focusing or Inhibitory Control scales. Alphas for the Attention Focusing, Attention Shifting, and Inhibitory Control scales at T1 were $.74, .80$, and .85 for mothers and $.85, .85$, and .88 for teachers, respectively. T2 alphas for these variables were $.72, .79$, and .81 for mothers and .82 .89 , and .90 for teachers, respectively. At T1 and T2, attention focusing was positively correlated with attention shifting and inhibitory control, and attention shifting was positively correlated with inhibitory control for both mothers and teachers: at T1, $r \mathrm{~s}(193-194)=.39$, .61 , and $.74, p s<.01$, respectively, for mothers, and $r \mathrm{~s}(181)=.61, .78$, and $.74, p \mathrm{~s}<.01$, respectively, for teachers; at $\mathrm{T} 2, r \mathrm{~s}(173)=.47, .63$, and $.71, p \mathrm{~s}<.01$, respectively, for mothers, and $r \mathrm{~s}(168-170)=.53, .71$, and $.78, p \mathrm{~s}<.01$, respectively, for teachers. Therefore, the scales were averaged within reporter to form composite mother- and teacher-report measures of regulation.

Observed regulation. Persistence during the puzzle task was used as an observational index of behavioral regulation at $\mathrm{T} 1$ and $\mathrm{T} 2$. While the mother completed a series of questionnaires, the child was unobtrusively videotaped engaging in a puzzle task. The child was shown a wooden box that contained a puzzle with geometric-shaped pieces. The box was constructed with a clear Plexiglas back (so that children's hand movements could be observed) and a cloth-covered front that had sleeves through which the children placed their arms. An experimenter instructed the child to assemble the puzzle without looking at it. However, although the cloth at the front of the box blocked the child's view of the puzzle, it was not attached at the bottom and could be easily lifted so the child could cheat by looking at the puzzle. Children were told that if they finished the puzzle within the allotted time ( $5 \mathrm{~min}$ at $\mathrm{T} 1 ; 4 \mathrm{~min}$ at $\mathrm{T} 2$ ), they would receive an attractive prize. A timer was set for the allotted minutes and placed in front of the child so that he or she would know how much time was left. The experimenter left the room during the puzzle task until the child called him or her back by ringing a bell or until the timer went off. The amount of time children persisted on the puzzle task rather than being off task or cheating (i.e., lifting up the cloth to look at the puzzle) was coded by two observers as well as by a reliability coder (different people coded persistence and maternal emotion). The time a child spent persisting was divided by the total time he or she spent on the puzzle task. Interrater reliabilities (based on 111 observations for $\mathrm{T} 1$ and 79 observations for $\mathrm{T} 2$ ) for $\mathrm{T} 1$ and $\mathrm{T} 2$ observed persistence were .97 and .98 , respectively.

\section{Children's Adjustment and Social Competence}

Externalizing behaviors. Mothers completed the CBCL, and teachers completed the Teacher Report Form (TRF; Achenbach, 1991a, 1991b). Items for the Externalizing scale were used to assess externalizing behavior. The experts' ratings for 3 out of 25 items for teacher-rated aggression (i.e., Items 77, 93, and 104, which concerned being loud, talking too much, and being easily frustrated) and 2 out of 20 items for parent-rated aggression (Items 93 and 104) resulted in a score under 3.00, so these items were deleted from the subscale. At T1 and T2, externalizing behaviors were measured by the sum of 31 mother-reported items and 30 teacher-reported items (each was coded from 0 to 2 per standard procedures). The alphas for the overall unconfounded Externalizing scale were .90 and .95 at T1 and .89 and .96 at T2 for mothers and teachers, respectively.

Internalizing behaviors. As is typical, the Anxious/Depressed, Withdrawn, and Somatic Complaints subscales of the CBCL and the TRF were used to assess internalizing behaviors. On the basis of the expert ratings, three out of nine items for the Withdrawn subscale for parents and teachers were deleted (i.e., Items 42, 75, and 102, which concerned being slow moving, preferring to be alone, and being shy). In addition, 2 out of 18 total items for the Anxious/Depressed scale for teachers (i.e., Items 71 and 81, relating to self-consciousness and feeling hurt when criticized) and 1 out of 14 items for mothers (regarding self-consciousness) were rated as measuring temperament more than psychopathology. At T1 and T2, internalizing behaviors were measured by the sum of 27 mother-reported items and 30 teacher-reported items. For the corrected Internalizing scale, alphas for mothers and teachers were .83 and .86 , respectively, at T1 and .87 and .89 at $\mathrm{T} 2$.

Social competence. Two subscales of a scale developed by Eisenberg et al. (2000) were used to assess social competence. Socially Appropriate 
Behavior was the average of four items (e.g., "This child is usually well behaved"; alphas at T1 were .79 for mothers and .89 for teachers; T2 alphas were .77 for mothers and .87 for teachers). Popularity was assessed by the mean of three items (e.g., "This child has a lot of friends"; alphas at T1 were .84 for mothers and .93 for teachers; $\mathrm{T} 2$ alphas were .76 for mothers and .91 for teachers). Mothers' reports of socially appropriate behavior and popularity were positively correlated at $\mathrm{T} 1, r(197)=.46, p<.001$, and at $\mathrm{T} 2, r(174)=.43, p<.01$, as were teachers' reports at $\mathrm{T} 1, r(179)=.57$, $p<.01$, and at $\mathrm{T} 2, r(170)=.59, p<.01$. Thus, the scales were averaged within reporter to form separate measures of parents' and teachers' reports of social competence.

\section{Results}

Table 1 contains the untransformed means and standard deviations for the major variables at T2 (for descriptive analyses and relations among constructs at T1, see Eisenberg, Gershoff, et al., 2001). Variables that were not normally distributed (skew/SE $>2$

Table 1

Means, Standard Deviations, and Skews for Variables at Time 1 (T1) and Time 2 (T2)

\begin{tabular}{lrrrr}
\hline \multicolumn{1}{c}{ Measure } & $M$ & $S D$ & \multicolumn{1}{c}{ Skew } \\
\hline & Mother report & & & \\
& & & & \\
T1 Positive expressivity & 7.31 & 0.99 & $-5.32(-0.11)$ \\
T1 Negative expressivity & 3.99 & 1.23 & $2.43(-0.10)$ \\
T1 Regulation & 4.40 & 0.76 & -1.43 & \\
T1 Externalizing & 15.22 & 8.94 & 3.85 & $(0.46)$ \\
T1 Internalizing & 9.55 & 6.61 & 7.33 & $(1.44)$ \\
T1 Social competence & 3.19 & 0.58 & $-6.03(-1.21)$ \\
T2 Positive expressivity & 7.35 & 1.00 & -5.91 & $(0.45)$ \\
T2 Negative expressivity & 3.86 & 1.16 & $1.78(-0.15)$ \\
T2 Regulation & 4.53 & 0.77 & $-1.16(-1.16)$ \\
T2 Externalizing & 12.65 & 7.99 & 4.20 & $(0.72)$ \\
T2 Internalizing & 8.54 & 6.89 & $6.63 \quad(1.89)$ \\
T2 Social competence & 3.22 & 0.56 & $-4.83(-0.75)$ \\
\hline
\end{tabular}

Teacher report

\begin{tabular}{lrrrr} 
T1 Regulation & 4.91 & 1.00 & -1.16 & \\
T1 Externalizing & 8.36 & 10.54 & 8.96 & $(0.33)$ \\
T1 Internalizing & 4.22 & 5.14 & 10.23 & $(0.86)$ \\
T1 Social competence & 3.16 & 0.70 & -3.82 & $(0.49)$ \\
T2 Regulation & 4.80 & 1.04 & -2.18 & \\
T2 Externalizing & 9.21 & 11.63 & 9.97 & $(0.05)$ \\
T2 Internalizing & 5.88 & 6.74 & 9.08 & $(0.05)$ \\
T2 Social competence & 3.11 & 0.73 & -3.84 & $(-0.57)$ \\
\hline & & & & \\
& Observed & & & \\
T1 Regulation & & & & \\
T1 Positive expressivity & 0.55 & 0.30 & -0.12 & \\
T1 Negative expressivity & 2.49 & 0.67 & 2.94 & \\
T2 Regulation & 1.22 & 0.32 & 11.62 & $(8.41)$ \\
T2 Positive HK & 0.68 & 0.29 & -3.02 & \\
T2 Positive MC & 4.09 & 1.03 & -6.82 & \\
\hline
\end{tabular}

Note. All measures besides expressivity pertain to the children. The means and standard deviations presented are those prior to transformations. Skew $=$ skew statistic/standard error of the skew (prior to transformation). Skews after transforming variables to reduce the skew appear in parentheses (variables such as observed maternal expressivity that were not the same across time were not transformed at either time). Positive $\mathrm{HK}=$ positive expressivity during hook-up procedure. Positive $\mathrm{MC}=$ positive expressivity during the mother-child interaction. or $<-2$ ) were transformed using either logarithmic or square root transformations (depending on the nature of the skew [Tabachnick \& Fidell, 1996] and using the same transformation at both T1 and T2 for the same measures at the two assessments), and all analyses were based on transformed scores. The one exception was for observed regulation at T2; it had a slight skew at T2 (3.02) but was not skewed at $\mathrm{T} 1$, and thus it was not transformed.

\section{Descriptive Analyses}

A MANOVA on the T2 variables by children's sex was significant, $F(13,140)=2.41, p<.01$. This was mainly due to significant univariate effects of sex on teachers' reports of children's regulation, social competence, and externalizing problem behaviors, $F \mathrm{~s}(1,152)=13.01,5.38$, and $6.24, p \mathrm{~s}<.01, .02$, and .01 , respectively. Teachers reported that girls were more regulated and socially competent and displayed fewer externalizing problems $(M \mathrm{~s}=5.14,3.26$, and 6.46, respectively) than boys ( $M \mathrm{~s}=4.51,2.97$, and 11.60 , respectively). The only variable that was significantly correlated with age was teacher-reported social competence; older children were rated as more socially competent by their teachers, $r(170)=.19, p<.01$.

To determine if SES was associated with any of the T2 variables measured, we created a composite of standardized measures of mother education, father education, and family income and correlated it with the main variables (sometimes one or more of these variables was missing). SES was significantly positively correlated both with mothers' observed positive expressivity during the hook-up and the mother-child interaction, $r s(159$ and 160) $=.29$ and $.20, p s<.01$, respectively, and with teachers' reports of regulation, $r(170)=.25, p<.01$, and negatively related to mothers' and teachers' reports of externalizing behaviors, $r \mathrm{~s}(175$ and 170) $=-.15$ and $-.20, p s<.05$ and .01 , respectively. Correlations were similar when income alone was used as the index of SES.

\section{Relations Among Constructs}

Correlations among various constructs were examined at T1 and T2 and between T1 and T2. Mothers' reported and observed positive emotional expressivity were positively related at $\mathrm{T} 2$; reported (but not observed) positive expressivity was negatively related to reported dominant negative expressivity (see Table 2). Teachers' and mothers' reports of regulation, externalizing, and social competence were significantly related across reporters; and as is commonly found (Achenbach, McConaughy, \& Howell, 1987), reports of internalizing were not significantly related across reporters. Moreover, persistence on the puzzle task was significantly related to teachers' reports of regulation.

Although not all of the zero-order correlations reflecting hypothesized relations were significant, the majority of correlations among variables at $\mathrm{T} 2$ were in the expected direction (see Table 2). There was only one unexpected finding: Although mothers' expression of dominant negative emotion was significantly associated with their reports of children's low regulation and high levels of internalizing and externalizing problems, it also was modestly correlated with higher levels of teacher-reported regulation. This finding contrasts with the marginal negative relation and the significant negative relation between teachers' reports of regulation at 


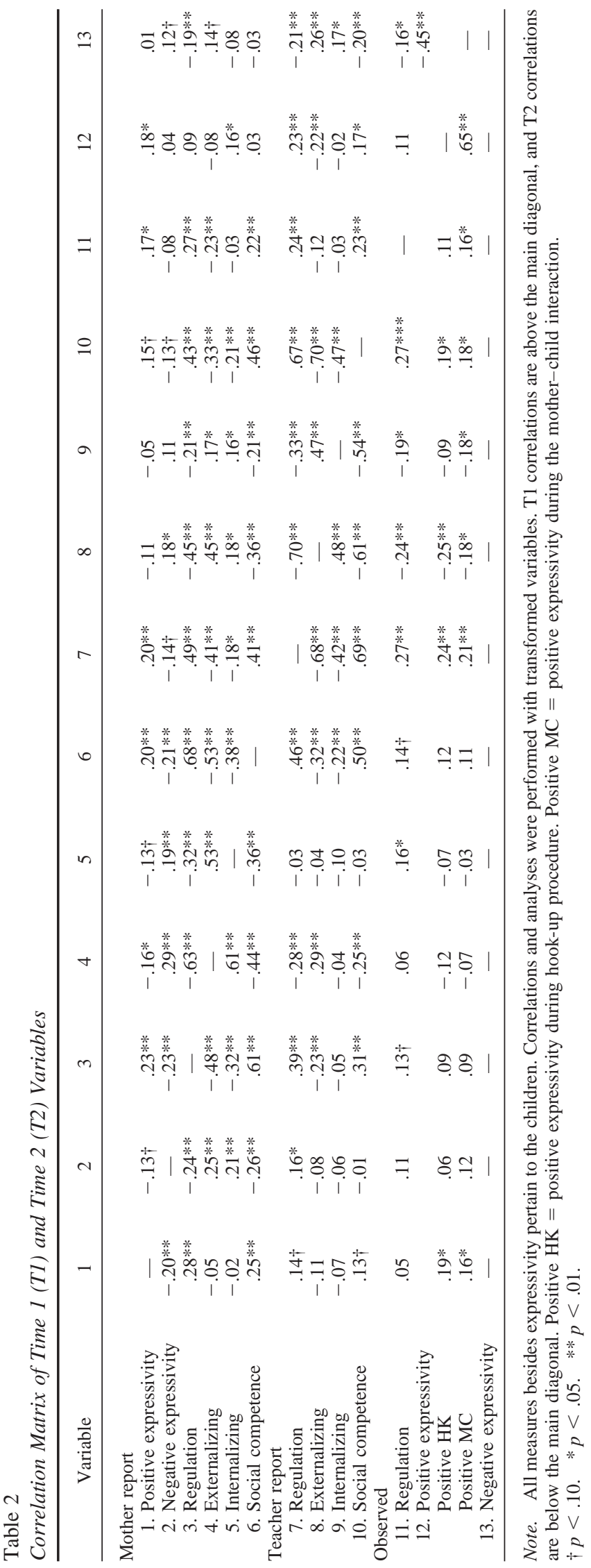

$\mathrm{T} 1$ and $\mathrm{T} 1$ mother-reported and $\mathrm{T} 1$ observed negative expressivity, respectively (see Table 2).

When child sex, age, and family SES variables were partialed from the T2 zero-order correlations presented in Table 2, relations were highly similar. Thus, similar to the findings at T1 (Eisenberg, Gershoff, et al., 2001), controlling for children's sex, age, and SES did not attenuate the overall pattern of relations. ${ }^{4}$

Correlations of constructs over time are presented in Table 3. With the exception of teacher-reported internalizing problems, all major variables were significantly positively related over time, indicating modest stability. Moreover, related constructs such as negative and positive emotionality often correlated in the expected direction over time.

\section{Structural Equation Models}

We used Mplus (Muthen \& Muthen, 1998), an SEM program that can be used with missing data, to test our hypothesis that children's regulatory abilities would mediate the association between mothers' emotional expressivity and children's adjustment. First a model was computed for the T2 data only (the T1-only model is presented in Eisenberg, Gershoff, et al., 2001); then a longitudinal model was tested.

\section{T2 Model}

Because estimates of the relations among latent variables may be positively biased when one uses the same reporters for latent variables, the within-reporter covariances among the error terms of indicators were estimated (i.e., error terms for mothers' report on one variable were correlated with error terms for their reports on other measures; covariances between errors for teachers' and parents' measures or the behavioral measure were not estimated; Kenny \& Kashy, 1992; Thomson \& Williams, 1984). (The model would not converge without these covariances.) As with the model presented by Eisenberg, Gershoff, et al. (2001), we did not need to add a covariance between positive and negative expressivity (the latent variables); disturbances among the three endogenous latent constructs were allowed to covary. The measurement-error covariances are not presented in Figures 1 and 2, in order to simplify the presentation.

On the basis of the CFI (comparative fit index) and the RMSEA (root mean square error of approximation), the $\mathrm{T} 2$ hypothesized model fit the data well: $\mathrm{CFI}=1.00 ;$ RMSEA $<.001$ (confidence intervals for the RMSEA $=.00$ to .048$) ; \chi^{2}(37, N=177)=34.51$, $n s$. However, the $R^{2}$ for internalizing problem behaviors could not be correctly estimated, probably because mothers' and teachers' reports of internalizing behaviors were not significantly correlated. Rather than set the measurement error variance of internalizing to

\footnotetext{
${ }^{4}$ Submissive negative emotion (softer, less assertive negative emotional expressivity, Halberstadt et al., $1995 ; \alpha \mathrm{s}=.70$ at $\mathrm{T} 1$ and .71 at T2) was fairly stable over time, $r(162)=.60, p<.01$, and was positively related to mothers' reports of dominant negative expressivity, externalizing problems, and internalizing problems, $r \mathrm{~s}(173)=.43, .16$, and $.20, p \mathrm{~s}<.01, .03$, and .01 , respectively, and negatively related to mother-reported regulation, $r(172)=-.22, p<.01$. It was not significantly related to any $\mathrm{T} 2$ measures that were not mother-reported.
} 


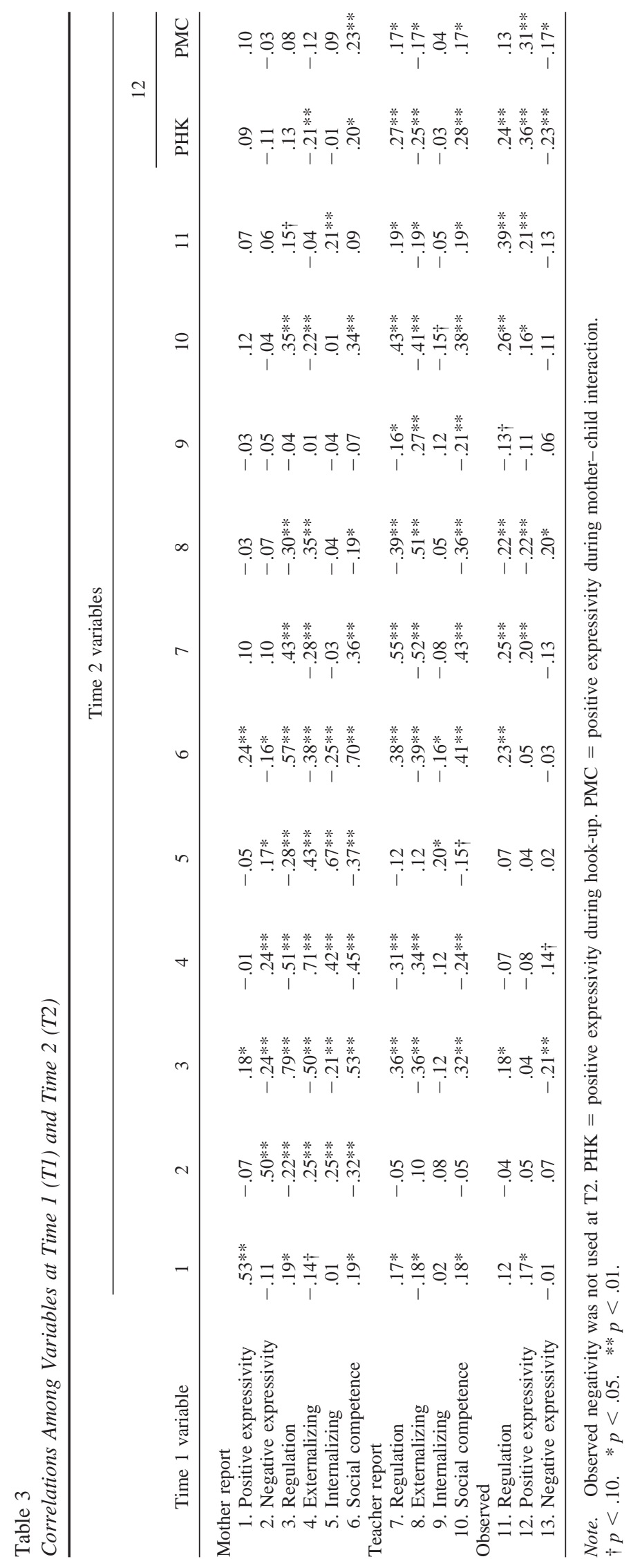


zero (doing this would make the $R^{2}$ of the latent variable equal to 1.00), we chose to use teachers' report of internalizing behaviors as the sole indicator of the latent variable. This model fit the data well: $\chi^{2}(32, N=177)=30.51, n s ;$ CFI $=1.00$; RMSEA $<.001$ (confidence intervals for the RMSEA $=.00$ to .052 ). The nonstandardized and standardized parameter estimates are presented in Figure 1. In addition to the paths in Figure 1, there was a marginal negative relation between the disturbances of internalizing behavior and social competence, $z=-1.68, p<.10 .^{5}$

As predicted, mothers' positive expressivity was positively related to children's regulation. ${ }^{6}$ Unexpectedly, mothers' expression of negative emotion was also positively related to children's regulation. Children's regulation was significantly negatively related to both externalizing and internalizing problem behaviors and positively related to social competence. On the basis of tests of the significance of mediated effects (using MacKinnon's, 1994, methods; also see MacKinnon, Lockwood, Hoffman, West, \& Sheets, 2002), regulation significantly mediated the effects of maternal positive expressivity on externalizing problem behaviors and social competence, $z \mathrm{~s}=-2.77$ and $2.80, p \mathrm{~s}<.05$, respectively; mediation for internalizing by regulation was marginally significant, $z=-1.83, p<.07$. Regulation marginally mediated the relations between maternal negative expressivity and externalizing problem behaviors and social competence, $z \mathrm{~s}=-1.94$ and 1.95, $p s<.06$. $^{7}$

When direct paths from positive and negative expressivity to externalizing behaviors, internalizing behaviors, and social competence were added to the model, the paths for externalizing behavior and social competence were still significantly mediated (the path from regulation to internalizing was nonsignificant) and only one of the six direct paths, a negative path from negative expressivity to social competence, was significant. Although the model fit the data well, $\chi^{2}(26, N=177)=19.68, n s, \mathrm{CFI}=1.00$, RMSEA $=.001$ (confidence intervals for the RMSEA $=.00$ to .039), the change in fit was not significant, $\chi^{2}(6, N)=10.83$, $n s$. Thus, for parsimony, the direct paths were not included (at T1, none of the direct paths was significant, and adding them did not improve the fit of the model). This pattern of findings suggests that the relations reported by Eisenberg, Gershoff, et al. (2001) for positive expressivity were still present 2 years later. However, the negative relation of negative expressivity to low regulation that was found at $\mathrm{T} 1$ was not obtained at $\mathrm{T} 2$.

\section{Longitudinal Model}

To examine the longitudinal relations among the variables, we specified a model in which the T2 model presented in Figure 1 was added to the T1 model presented by Eisenberg, Gershoff, et al. (2001). (See Table 3 for correlations between T1 and T2 variables.) As in the T2-only model, we used only teacher-reported internalizing problems as an indicator of this construct at T2. In addition to estimating the within-reporter covariances at each time period, we estimated the covariances of mothers' reports of the same constructs across T1 and T2 (e.g., the error term for the observed construct of mother-reported regulation at T1 was correlated with the error term for mothers' reports of regulation at T2) as well as for the puzzle task across the two assessments. We did not estimate the covariances between teachers' reports at T1 and $\mathrm{T} 2$ because different teachers reported on children's behaviors at the two time points. Because we were interested in comparing rela- tions across time, we also set the loadings on $\mathrm{T} 1$ latent variables equal to the equivalent loadings on the T2 latent variables (because only two indicators per latent variable need to be equal to each other, the observed indicators for regulation were not set to be equal). ${ }^{8}$

The initial model provided a marginal fit, $\chi^{2}(218, N=208)=$ $325.93, p<.01, \mathrm{CFI}=.95, \mathrm{RMSEA}=.049$ (confidence intervals for the RMSEA $=.037$ to .059), and the modification indices (Lagrange multiplier statistics) indicated that we should add covariances between error terms for mothers' reports of social competence at T1 and mothers' reports of negative dominant expressivity at T2, mothers' reports of internalizing problems at T1 and mothers' reports of externalizing problems at $\mathrm{T} 2$, and mothers' reports of externalizing problems at $\mathrm{T} 1$ and mothers' reports of social competence at T2. With $\chi^{2}(215, N=208)=281.76, p<$ $.01, \mathrm{CFI}=.97$, and RMSEA $=.039$ (confidence intervals for the RMSEA $=.025$ to .051 ), this model provided a significantly better fit than the initial model, change in $\chi^{2}(3)=44.17, p<.01$.

However, because there were Heywood cases (negative estimates of measurement error) for the latent constructs of externalizing and regulation at $\mathrm{T} 2$, per standard practice their error terms ( $d \mathrm{~s}$ ) had to be set to 0 . When this is done, the $R^{2}$ cannot be estimated accurately for those two variables. Although the chisquare was significant for this model, $\chi^{2}(217, N=208)=282.99$, $p<.01$, both the CFI (.966) and the RMSEA (.038, confidence interval for the RMSEA $=.024$ to .050 ) indicated the model fit the data well. ${ }^{9}$ As presented in Figure 2, the paths between the T1 latent variables were all significant and in the predicted directions. In addition, all autoregressive (across-time) paths, except for internalizing problem behaviors, were significant. At T2, the only significant path (when the autoregressive paths were included in the model) was the positive path between maternal negative expressivity and children's regulation. Moreover, adding three direct paths from maternal negative expressivity to $\mathrm{T} 2$ developmental

\footnotetext{
${ }^{5}$ Measurement models also were run prior to adding the paths, separately for $\mathrm{T} 1$ and $\mathrm{T} 2$. The chi-squares were nonsignificant, the CFIs were .987 or better, and the RMSEAs were .037 or better.

${ }^{6}$ The model was highly similar if the measure of maternal positive expressivity included only the average of the four 30-s affect coding periods and not ratings of warmth during this period.

${ }^{7}$ When maternal reports of internalizing were the sole index of internalizing in the model, the path from regulation to internalizing was nonsignificant.

${ }^{8}$ When we tested whether the paths could be constrained across the two ages (comparing one path at a time for constrained vs. unconstrained models), we found that the paths from positive or negative expressivity to regulation, and the path from regulation to externalizing problems, were significantly different at the two ages (so the paths were not constrained to be equal across age). Constraining the remaining two paths from regulation to internalizing and from regulation to social competence resulted in an autoregressive (across-time) path that clearly should be significant; thus, those two paths were also left unconstrained.

${ }^{9}$ There were two standardized coefficients slightly greater than 1.0 in the longitudinal model. This condition occurs when variables are highly related, which was clearly the case for the two instances in the model- the autoregressive correlations of regulation and externalizing problems over time (see Table 2). This does not indicate an error or problem with the model.
} 


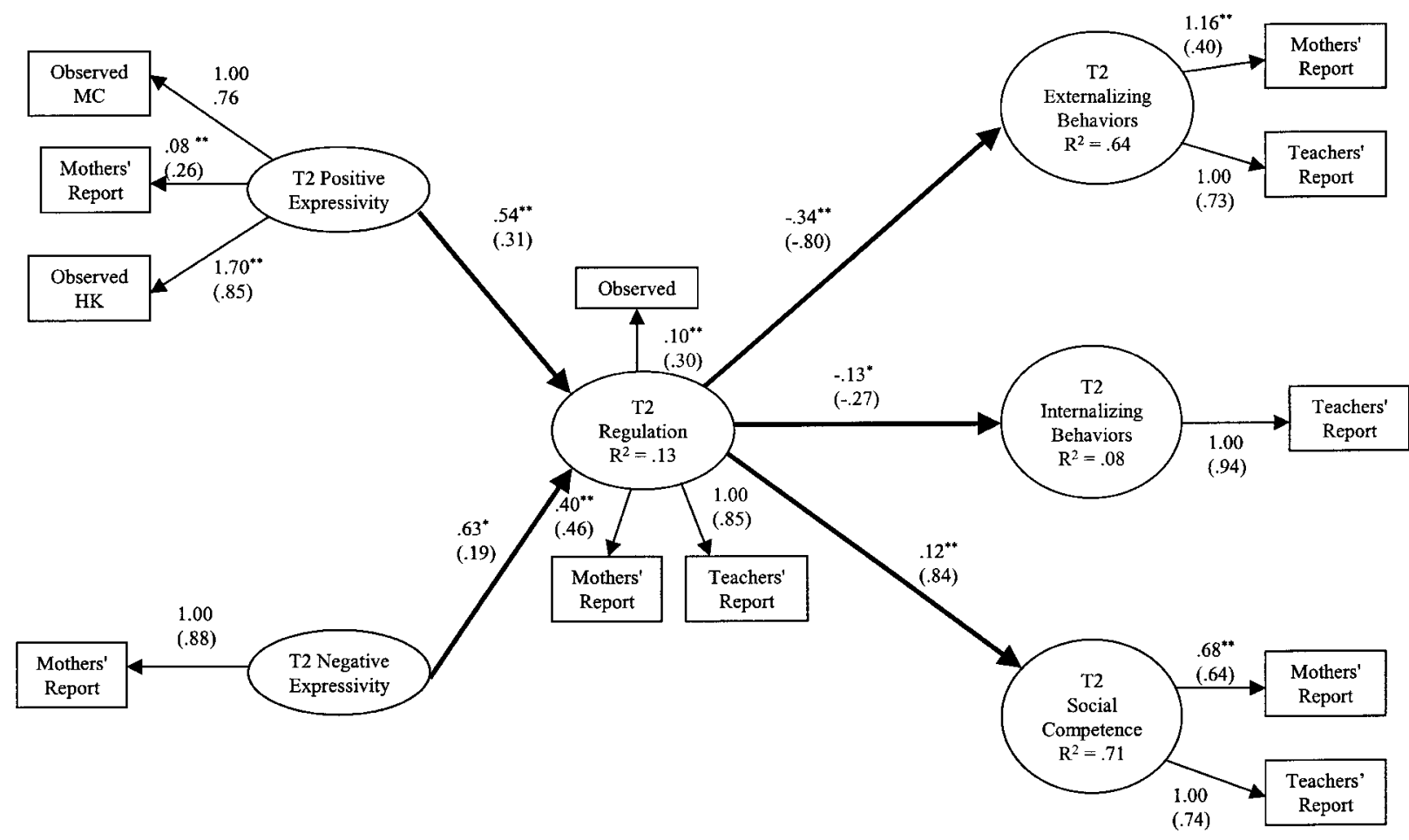

Figure 1. The T2 (Time 2) mediated model with unstandardized estimates (standardized estimates are in parentheses). Solid lines represent significant paths. Observed HK = observed positive expressivity during hook-up; Observed $\mathrm{MC}=$ observed positive expressivity during mother-child interaction. ${ }^{*} p<.05 .{ }^{* *} p<.01$.

outcomes did not improve the fit of the model or result in any additional significant paths.

Because maternal negative expressivity was observed at T1 but not $\mathrm{T} 2$, we recomputed the model, dropping $\mathrm{T} 1$ observed negative expressivity so that the negative expressivity construct would be the same at both T1 and T2. This model fit well: $\chi^{2}(196, N=$ $208)=252.71, p<.01, \mathrm{CFI}=.97, \mathrm{RMSEA}=.037$ (confidence interval for the RMSEA $=.022$ to .050 ). The pattern of findings was the same as in Figure 2. Moreover, it could be argued that differences in the samples at $\mathrm{T} 1$ and $\mathrm{T} 2$ caused the differences in patterns. Therefore, we estimated the longitudinal model using only participants who had data at $\mathrm{T} 1$ and $\mathrm{T} 2$ and whose mothers came to the laboratory both times. The model fit was similar to that of the model in Figure 2, $\chi^{2}(217, N=171)=284.07, p<.01$, $\mathrm{CFI}=.96$, RMSEA $=.043$ (confidence interval for the RMSEA $=.027$ to .056). All loadings of observed variables on the latent constructs remained significant with the exception that the loading for T1 mothers' report of internalizing problem behaviors became marginally significant (rather than significant). The negative path from negative expressivity at $\mathrm{T} 1$ to regulation at $\mathrm{T} 1$ also became marginally significant. The significance levels of all other paths remained very similar. These slight drops in significance likely are due merely to the smaller sample size.

\section{Tests of Moderation by Sex of the Child, Age of the Child, and SES of the Family}

Using Box's $M$ statistic, we tested whether the covariance matrices differed for boys and girls, for older and younger chil- dren, or for lower and high SES (e.g., the average of maternal education and income) families (Winer, 1971; based on a median split). Because Eisenberg, Gershoff, et al. (2001) already reported that these variables did not moderate the T1 model, we tested for moderation only at T2 and in the longitudinal model. Results indicated that child sex, age of the child, and family SES did not moderate results in the T2 or longitudinal models. ${ }^{10}$ However, these tests for potential moderation may be weak because of the limited sample size, even though Box's $M$ is a sensitive test.

\section{Regression Analyses}

Our test of mediation in the SEM model was slightly conservative (MacKinnon et al., 2002); moreover, the longitudinal model did not have optimal power because of the covariances between error terms (which were due to teacher or parent method relations, as recommended by Kenny \& Kashy, 1992). Thus, we computed regression models to see if the findings were similar in regard to mediation. Indicators of a given construct (e.g., maternal positive expressivity) were standardized and averaged for use in these analyses. Then we used the joint significance test to assess medi-

\footnotetext{
${ }^{10}$ On the basis of Teti and Cole's (1995) suggestion that risk status moderates the relation between negative expressivity and externalizing problems, we also examined whether high- or low-risk status (based on median scores for the average of teachers' and mothers' reports of externalizing problems) moderated the relations at T2. According to Box's $M$ test, it did not.
} 


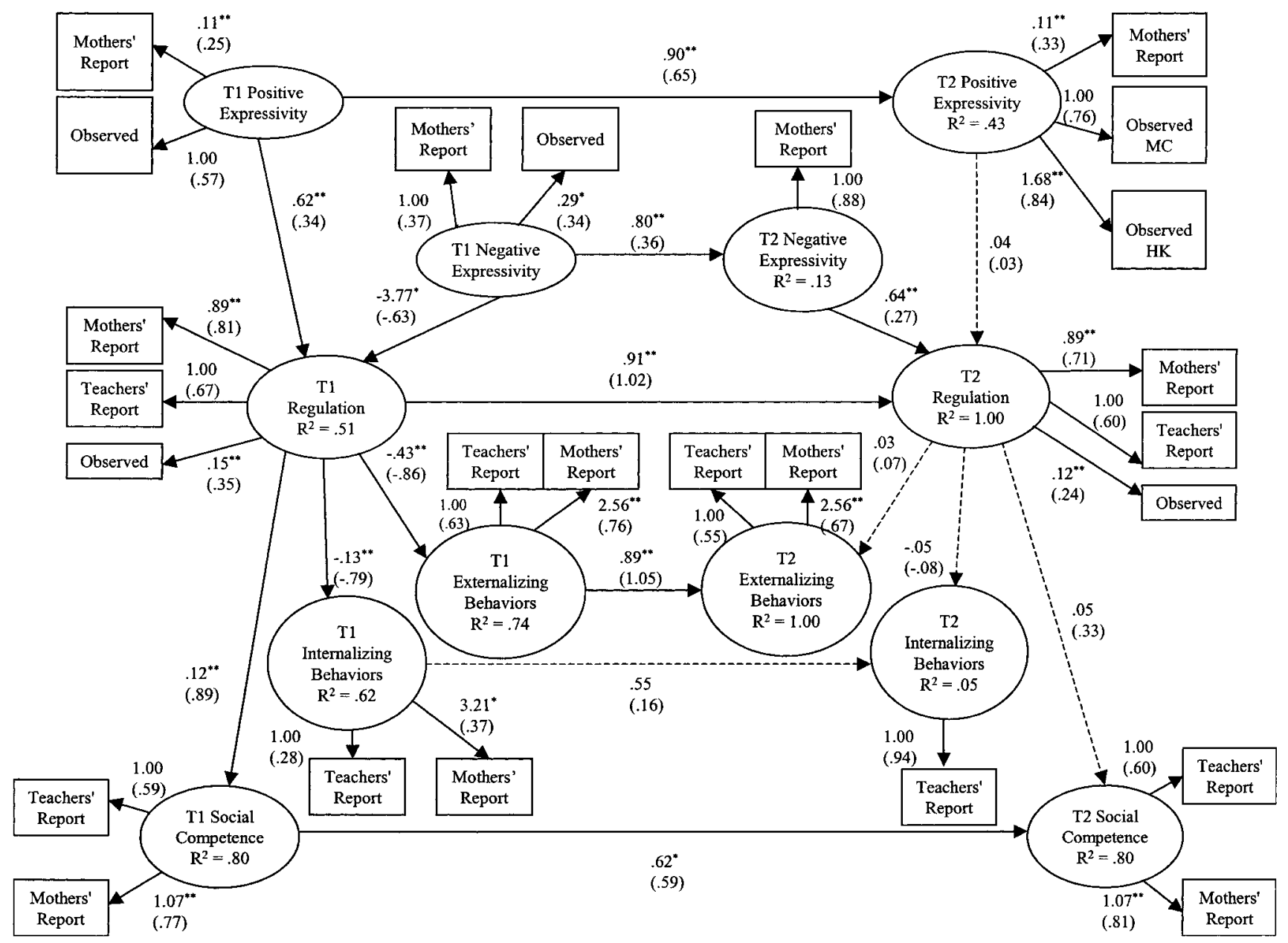

Figure 2. The longitudinal model $(\mathrm{T} 1=$ Time $1, \mathrm{~T} 2=$ Time 2$)$ with unstandardized estimates (standardized estimates are in parentheses). Solid lines represent significant paths, and dotted lines represent nonsignificant paths. $R^{2} \mathrm{~s}$ at T2 for externalizing and regulation are not accurate because the variance of these constructs had to be set to 0 (because of Heywood cases). *p $<.05$. **p $<.01$.

ation (MacKinnon et al., 2002); this procedure was recommended by MacKinnon et al. because of its power and its accurate Type 1 error rates. It requires computation of the two regressions: one in which the independent variable predicts the mediator and one in which the independent variable and the mediator jointly predict the dependent variable. The independent variable must predict the mediator in the first equation, and the mediator must predict the dependent variable in the second equation. For example, to examine whether the relation of $\mathrm{T} 2$ positive maternal expressivity to parent externalizing at $\mathrm{T} 2$ was mediated by $\mathrm{T} 2$ regulation, we computed a regression in which $\mathrm{T} 2$ externalizing was the dependent variable and the $\mathrm{T} 1$ values for maternal positive expressivity, child regulation, and child externalizing were entered on the first step (to control for their consistency, similar to the situation with the longitudinal SEM model) and T2 maternal expressivity and regulation were entered on the second step. Another regression, predicting $\mathrm{T} 2$ regulation (the mediator) was computed in which the two T1 variables were entered on the first step and maternal positive expressivity was entered on the second step.
For negative expressivity, there was no evidence of mediation because negative expressivity did not significantly predict child regulation when the $\mathrm{T} 1$ values of the variables were controlled. However, T2 maternal positive expressivity did predict T2 child regulation (when T1 levels of these variables were controlled): change in $R^{2}$ at Step $2=.02, F(1,166)$ for the change $=5.32, p<$ $.02, \beta=.15$. Moreover, when maternal positive expressivity and child regulation were used to predict $\mathrm{T} 2$ externalizing problems, social competence, or internalizing problems (teacher-rated), the changes in $R^{2}$ s were $.04, .11$, and .08 , respectively; $F$ s for the respective $R^{2}$ changes $(d f \mathrm{~s}=2,164 ; 2,163$; and 2,159$)$ were $7.82,20.58$, and $6.98, p \mathrm{~s}<.01$, and the betas for regulation were $-.29, .45$, and -.36 . Mediation was not significant for mothers' reports of internalizing problems. Of course, there are a number of differences in the SEM and regressions procedures; for example, measures of a construct were weighted equally in the regressions and not in the SEM, and the SEM model estimated error terms and included more paths at once. The lack of findings for maternal expression of negative emotion may have been partly 
due to the fact that the SEM model weighted teachers' reports of regulation somewhat more than parents' reports, whereas both reporters were weighted equally in the regression analysis. Nonetheless, the regressions suggested that the relations of maternal positive expressivity to children's regulation and problem behavior held at T2 (when T1 variables were controlled) and that these relations were mediated by children's effortful regulation.

\section{Discussion}

Several findings in this study are particularly noteworthy. First, for the T2-only model, maternal positive emotional expressivity was positively related to children's regulation, and regulation mediated the relation of maternal positive emotional expressivity to children's externalizing problems and social competence. Thus, the relation of maternal positive expressivity to measures of children's social functioning was still evident 2 years later, and this pattern of findings provided a near replication of analogous positive expressivity data from 2 years before.

When the longitudinal model was tested, the lack of findings for maternal positive expressivity at $\mathrm{T} 2$ suggested that the relations for maternal positive expressivity obtained at $\mathrm{T} 2$ in the concurrent model likely were already in place at $\mathrm{T} 1$ and were due to consistency across time in the variables measured at $\mathrm{T} 1$. The stabilities (autoregressive paths) for maternal positive expressivity and children's regulation, externalizing, and social competence (but not internalizing) were relatively high, which might account for the fact that relations among these variables dropped to nonsignificance at $\mathrm{T} 2$ when stability from $\mathrm{T} 1$ to $\mathrm{T} 2$ was taken into account in the longitudinal model. However, in the regression analyses, in which $\mathrm{T} 1$ regulation, expressivity, and child outcomes were controlled, T2 maternal expressivity did predict regulation, and the latter appeared to mediate relations to social competence and adjustment. It is not clear whether the difference in the procedures or the limited power in the SEM analysis accounted for this difference in the pattern of findings. In any case, it is clear that the relations between positive maternal expressivity and children's regulation and social functioning/adjustment persisted at $\mathrm{T} 2$; it simply is not obvious whether T2 maternal expressivity uniquely predicted children's regulation and social functioning above and beyond prediction from the $\mathrm{T} 1$ variables.

Thus, we can say relatively little about causal effects of maternal positive expressivity at T2. At T1 (Eisenberg, Gershoff, et al., 2001), the findings best supported a parent-driven model, with parent expressivity affecting children's regulation and social functioning (it did not make sense to compute reverse models at T2 because most $\mathrm{T} 2$ relations were nonsignificant when $\mathrm{T} 1$ variables were included in the model). However, the T1 data were concurrent, so it is unclear whether at an earlier age children's characteristics served to elicit (or inhibit) maternal expression of positive emotion. Nonetheless, given that the same pattern of relations was obtained at T2 as at T1 (prior to controlling for T1), it is quite possible that causal relations were fairly stable over the 2 years between our assessments and that the associations among maternal positive expressivity and children's developmental outcomes did not change much as the children progressed through elementary school.

It is noteworthy that the correlations between positive maternal expressivity and regulation, social competence, and adjustment at
T2, especially for teachers' reports of these variables (see Table 2), were primarily for the observed rather than the reported maternal expressivity data. It is unclear why this was true. Perhaps with increasing age children differentiate more between maternal positive emotion directed at them and positive emotion directed toward others or expressed about social events or objects. If this is true, maternal positive emotionality not directed at children might have less of an impact on them with age. This pattern was not as clear at $\mathrm{T} 1$, so maternal bias may not explain the difference. Longitudinal work is needed to determine differences in how these two types of positive emotional expressivity (or measures of positive emotional expressivity) relate to children's behavior and adjustment as they mature.

The findings for maternal negative emotional expressivity were different from, and less expected than, those for positive emotional expressivity. At T1, maternal dominant negative emotionality predicted lower levels of children's regulation, whereas in the T2-only and longitudinal models, it was positively related to regulation. However, in the regression analyses, maternal negative expressivity at T2 did not predict children's regulation at T2 when T1 negative expressivity and regulation were controlled. On the basis of the correlations, it appears that the positive relation between negative expressivity and children's regulation in the SEM models was primarily for teachers' reports of regulation (which loaded more highly on the latent construct of regulation at T2); mothers' reports of regulation at $\mathrm{T} 2$ were negatively correlated with their reported dominant negative expressivity. It appears that changes in mothers' dominant negative expressivity may have affected changes in teachers' reports of children's regulation over 2 years. This finding is similar to one reported by M. T. Greenberg (personal communication, July 2, 2001) in which parental negative expressivity was related to teachers' reports of children's compliance at school (compliant children are likely to be viewed by teachers as regulated).

At T2, we did not have a measure of observed negative expressivity that was of adequate frequency for use, and part of the difference in findings could be due to this factor. However, observed maternal negative expressivity at T1 was significantly negatively correlated with mothers' reports of children's regulation at T2 and was nonsignificantly negatively related to teachers' reports of regulation at $\mathrm{T} 2$. Thus, the relation of $\mathrm{T} 1$ observed negative expressivity to children's regulation was similar for T1 and $\mathrm{T} 2$ regulation. Moreover, the findings were not due to different samples being included at $\mathrm{T} 1$ and $\mathrm{T} 2$ (the findings were similar when only families with maternal data at both times were included). Perhaps the configuration of child-rearing practices associated with a parenting style including the expression of dominant negative emotion at home promotes, over time, relatively inhibited behavior at school, which is interpreted by teachers as regulation. This explanation is consistent with the finding that T2 maternal negative dominant expressivity was negatively associated with children's mother-report adjustment and social competence.

Whatever the reason for the pattern of findings, it is clear that the negative relation between maternal negative expressivity and children's regulation that held at younger ages did not hold for teacher-reported regulation when the children were 2 years older. Indeed, this path in the model was significantly different at T1 and $\mathrm{T} 2$. Moreover, the fact that $\mathrm{T} 2$ dominant negative expressivity was negatively related to mothers' reports of children's regulation 
suggests that maternal emotional expressivity may have different correlates or outcomes at home and at school. It is also possible, however, that mothers' reports of their negative expressivity were influenced by social desirability or other biases, which may have resulted in the different patterns of associations at $\mathrm{T} 2$ (but not T1) for teacher and parent reports.

Another possible explanation for the modest positive relation between T2 maternal negative emotional expressivity and teacherreported adjustment is that as children age, they are less adversely affected by mothers' general expression of negative emotion. As suggested by Halberstadt et al. (1999), when parents express negative emotion in general (and not just toward children), children may not think about maternal emotional negativity as relevant to themselves. In contrast, when parents express negative emotion in response to children's behavior, children may be more likely to internalize that information as self-relevant. Children's selfrelevant negative beliefs (e.g., that they are unable to sit still or are unkind) may then affect their subsequent attempts at regulation or at engaging in more positive behaviors. Thus, for long-term development, maternal expression of negative emotion directed at children may be particularly likely to undermine their regulation and behavior. Of course, this relation does not negate some negative effects of viewing negative expressivity in the home, especially self-threatening hostile emotions that often occur during marital conflict (Cummings \& Davies, 1996). Moreover, because maternal reports of negative expressivity were relatively low, it is possible that they would have been associated with low regulation and problem behaviors if more mothers who expressed a great deal of this type of emotion had been included in the sample. In future work, it would be useful to assess the differential effects of maternal negative emotion directed at children and maternal negative emotion expressed toward others in the family.

There were weaker and less consistent relations between maternal expressivity and children's internalizing problems than between maternal expressivity and children's externalizing problems. Perhaps internalizing problems, in comparison to externalizing problems, are more closely linked to temperamental aspects of emotionality that are relatively difficult to modify. Moreover, as suggested by the pattern of correlations in this sample and by more detailed analyses on this issue at T1 (Eisenberg, Cumberland, et al., 2001), it may be that internalizing problems are less strongly linked to deficits in effortful control than are externalizing problems (which would reduce the likelihood of mediation effects).

Relations generally were a bit stronger for teachers' than for mothers' reports of internalizing, which is surprising given that teachers are generally believed to be less reliable reporters than mothers of such problems (Stanger \& Lewis, 1993). Perhaps teachers' reports reflected temperamental variables or social withdrawal more than did those of parents, which resulted in slightly different patterns of findings.

Because few of the correlations between T2 maternal expressivity and teachers' reports of regulation, adjustment, or social competence were significant, one might wonder if the findings were due only to maternal reports, which might possibly have been biased. However, some of the correlations between maternal expressivity and teacher-reported child regulation and social competence were marginally significant (in addition to the one significant correlation between maternal negative expressivity and children's regulation) or just below marginal significance. SEM procedures adjust for error variance (i.e., correct for attenuation). Moreover, because teachers' reports of regulation, externalizing, and social competence contributed to the latent constructs for these variables, there was evidence that the relations for these variables were not due solely to parents' reports.

As at T1, age, sex and SES did not moderate the pattern of relations found in this study at T2 (the model at T2 only appeared to be relatively powerful, as effects were obtained). This was true despite some sex and SES differences in variables. These findings argue for the robustness of the relations that were noted. However, it is quite possible that moderating effects would be found if the sample size was larger; thus, the lack of moderation must be viewed with caution. On the other hand, Box's $M$ is a sensitive statistic (i.e., it tends to pick up small differences in covariance matrices), which bolsters our confidence in the moderational analyses.

A number of methodological strengths to the study also bolster our confidence in the findings, including the use of multiple informants for most constructs and the longitudinal design. However, there are some limitations of the study that should be kept in mind. First and foremost, the data, albeit longitudinal, are correlational. Thus, no firm conclusions can be drawn in regard to causality. In addition, our measures of maternal negative emotional expressivity were not ideal. We observed too little negative emotion to use at T2. In addition, mean reports of dominant negative emotion were low, perhaps because of mothers' concerns about social desirability. In future work, it would be useful to include both observational and mother-reported measures of dominant and more submissive (less assertive) negative emotion. Another limitation of the study is that it is unclear whether our findings generalize to minority or low-income populations (although our sample was relatively diverse). Moreover, additional longitudinal work involving children younger than those in the present study is needed to identify the age at which relations between parental expressivity and children's regulation, adjustment, and social functioning first become established firmly enough to account for similar relations at older ages.

In summary, the findings in this study indicate that maternal emotional expressivity is related to children's adjustment and social competence and that for maternal positive expressivity, this relation is established early and maintained over some period of time. Moreover, the change in findings over the 2-year period for maternal negative dominant expressivity indicates that its relation to developmental outcomes may change with the age of the child. Relations of parental negative emotional expressivity to children's socioemotional development (e.g., expressivity) clearly are complex and may differ with the type of negative parental expressivity (Halberstadt et al., 1999; Halberstadt \& Eaton, in press). Moreover, because parental expression of emotion directed at a child might be expected to have stronger effects on children than parental emotions directed at others (if the same mode of measurement, such as self-report or observations, were used for both), in future work it may be worthwhile to use multiple measures assessing the relation of such parental expressivity to children's regulation, social functioning, and adjustment. Because several investigators have now found that parental negative expressivity sometimes predicts (or is related to) positive developmental outcomes for children, it is important to identify factors that moderate the valence of the relation between parental negative expressivity 
and children's emerging regulation, social functioning, and adjustment.

\section{References}

Achenbach, T. M. (1991a). Integrative guide for the 1991 CBCL/4-18, YSR, and TRF profiles. Burlington: University of Vermont, Department of Psychiatry.

Achenbach, T. M. (1991b). Manual for the Child Behavior Checklist/4-18 and 1991 Profile. Burlington: University of Vermont, Department of Psychology.

Achenbach, T. M., McConaughy, S. H., \& Howell, C. T. (1987). Child/ adolescent behavioral and emotional problems: Implications of crossinformant correlations for situational specificity. Psychological Bulletin, 101, 213-232.

Bates, J. E. (1990). Conceptual and empirical linkages between temperament and behavior problems: A commentary on the Sanson, Prior, and Kyrios study. Merrill-Palmer Quarterly, 36, 193-199.

Boyum, L. A., \& Parke, R. D. (1995). The role of family emotional expressiveness in the development of children's social competence. Journal of Marriage and the Family, 57, 593-608.

Bridges, L. J., \& Grolnick, W. S. (1995). The development of emotional self-regulation in infancy and early childhood. In N. Eisenberg (Ed.), Review of personality and psychology: Vol. 15. Social development (pp. 185-211). Thousand Oaks, CA: Sage.

Brody, G. H., \& Ge, X. (2001). Linking parenting processes and selfregulation to psychological functioning and alcohol use during early adolescence. Journal of Family Psychology, 15, 82-94.

Bronstein, P., Fitzgerald, M., Briones, M., Pieniadz, J., \& D’Ari, A. (1993). Family emotional expressiveness as a predictor of early adolescent social and psychological adjustment. Journal of Early Adolescence, 13, $448-471$.

Burrowes, B. D., \& Halberstadt, A. G. (1987). Self- and familyexpressiveness styles in the experience and expression of anger. Journal of Nonverbal Behavior, 11, 254-268.

Campos, J. J., Campos, R. G., \& Barrett, K. C. (1989). Emergent themes in the study of emotional development and emotion regulation. Developmental Psychology, 25, 394-402.

Cassidy, J., Parke, R. D., Butkovsky, L., \& Braungart, J. M. (1992). Family-peer connections: The roles of emotional expressiveness within the family and children's understanding of emotion. Child Development, 63, 603-618.

Cicchetti, D., Ackerman, B. P., \& Izard, C. E. (1995). Emotions and emotion regulation in developmental psychopathology. Development and Psychopathology, 7, 1-10.

Cohn, J. F., \& Tronick, E. Z. (1983). Three-month-old infants' reaction to simulated maternal depression. Child Development, 54, 185-193.

Cole, P. M., Michel, M. K., \& Teti, L. O. (1994). The development of emotion regulation and dysregulation: A clinical perspective. In N. A. Fox (Ed.), The development of emotion regulation: Biological and behavioral considerations. Monographs of the Society for Research in Child Development, 59 (2-3, Serial No. 240), 73-100.

Collins, W. A., Maccoby, E. E., Steinberg, L., Hetherington, E. M., \& Bornstein, M. H. (2000). Contemporary research on parenting: The case for nature and nurture. American Psychologist, 55, 218-232.

Crockenberg, S. (1985). Toddlers' reactions to maternal anger. MerrillPalmer Quarterly, 31, 361-373.

Cummings, E. M., \& Davies, P. (1996). Emotional security as a regulatory process in normal development and the development of psychopathology. Development and Psychopathology, 8, 123-139.

Darling, N., \& Steinberg, L. (1993). Parenting style as context: An integrative model. Psychological Bulletin, 113, 487-496.

Denham, S. A. (1989). Maternal affect and toddlers' social-emotional competence. American Journal of Orthopsychiatry, 59, 368-376.
Denham, S. A. (1998). Emotional development in young children. New York: Guilford Press.

Denham, S. A., Workman, E., Cole, P. M., Weissbrod, C., Kendziora, K. T., \& Zahn-Waxler, C. (2000). Prediction of externalizing behavior problems from early to middle childhood: The role of parental socialization and emotion expression. Development and Psychopathology, 12, $23-45$.

Denham, S. A., Zoller, D., \& Couchoud, E. A. (1994). Preschoolers' causal understanding of emotion and its socialization. Developmental Psychology, 30, 928-936.

Derryberry, D., \& Rothbart, M. K. (1997). Reactive and effortful processes in the organization of temperament. Development and Psychopathology, 9, 633-652.

Dix, T. (1991). The affective organization of parenting: Adaptive and maladaptive processes. Psychological Bulletin, 110, 3-25.

Dix, T. (1992). Parenting on behalf of the child: Empathic goals in the regulation of responsive parenting. In I. E. Sigel, A. V. McGillicuddyDeLisi, \& J. J. Goodnow (Eds.), Parental belief systems (Vol. 2, pp. 319-346). Hillsdale, NJ: Erlbaum.

Dunn, J., \& Brown, J. (1994). Affect expression in the family, children's understanding of emotions, and their interactions with others. MerrillPalmer Quarterly, 40, 120-137.

Dunn, J., Brown, J., \& Beardsall, L. (1991). Family talk about feeling states and children's later understanding of others' emotions. Developmental Psychology, 27, 448-455.

Dusek, J. B., \& Danko, M. (1994). Adolescent coping styles and perceptions of parental child rearing. Journal of Adolescent Research, 9, 412-426.

Eisenberg, N., Cumberland, A., \& Spinrad, T. L. (1998). Parental socialization of emotion. Psychological Inquiry, 9, 241-273.

Eisenberg, N., Cumberland, A., Spinrad, T. L., Fabes, R. A., Shepard, S. A., Reiser, M., et al. (2001). The relations of regulation and emotionality to children's externalizing and internalizing problem behavior. Child Development, 72, 1112-1134.

Eisenberg, N., Fabes, R. A., Carlo, G., Troyer, D., Speer, A. L., Karbon, M., \& Switzer, G. (1992). The relations of maternal practices and characteristics to children's vicarious emotional responsiveness. Child Development, 63, 583-602.

Eisenberg, N., Fabes, R. A., Guthrie, I. K., \& Reiser, M. (2000). Dispositional emotionality and regulation: Their role in predicting quality of social functioning. Journal of Personality and Social Psychology, 78, $136-157$.

Eisenberg, N., Fabes, R. A., Schaller, M., Miller, P. A., Carlo, G., Poulin, R., et al. (1991). Personality and socialization correlates of vicarious emotional responding. Journal of Personality and Social Psychology, 61, 459-470.

Eisenberg, N., Fabes, R. A., Shepard, S. A., Guthrie, I. K., Murphy, B. C., \& Reiser, M. (1999). Parental reactions to children's negative emotions: Longitudinal relations to quality of children's social functioning. Child Development, 70, 513-534.

Eisenberg, N., Gershoff, E. T., Fabes, R. A., Shepard, S. A., Cumberland, A. J., Losoya, S. H., et al. (2001). Mothers' emotional expressivity and children's behavior problems and social competence: Mediation through children's regulation. Developmental Psychology, 37, 475-490.

Eisenberg, N., Liew, J., \& Pidada, S. (2001). The relations of parental emotional expressivity with the quality of Indonesian children's social functioning. Emotion, 1, 107-115.

Gable, S., \& Isabella, R. A. (1992). Maternal contributions to infant regulation of arousal. Infant Behavior and Development, 15, 95-107.

Garner, P. W. (1995). Toddlers' emotion regulation behaviors: The roles of social context and family expressiveness. Journal of Genetic Psychology, 156, 417-430.

Garner, P. W., \& Power, T. G. (1996). Preschoolers' emotional control in the disappointment paradigm and its relation to temperament, emotional 
knowledge, and family expressiveness. Child Development, 67, 14061419.

Gottman, J. M., Katz, L. F., \& Hooven, C. (1997). Meta-emotion: How families communicate emotionally. Mahwah, NJ: Erlbaum.

Greenberg, M. T., Lengua, L. J., Coie, J. D., \& Pinderhughes, E. E. (1999). Predicting developmental outcomes at school entry using a multiple-risk model: Four American communities. Developmental Psychology, 35, 403-417.

Grusec, J. E. (1971). Power and the internalization of self-denial. Child Development, 42, 93-105.

Grusec, J. E., \& Goodnow, J. J. (1994). Impact of discipline methods on the child's internalization of values: A reconceptualization of current points of view. Developmental Psychology, 30, 4-19.

Halberstadt, A. G. (1986). Family socialization of emotional expression and nonverbal communication styles and skills. Journal of Personality and Social Psychology, 51, 827-836.

Halberstadt, A. G., Cassidy, J., Stifter, C. A., Parke, R. D., \& Fox, N. A. (1995). Self-expressiveness within the family context: Psychometric support for a new measure. Psychological Assessment, 7, 93-103.

Halberstadt, A. G., Crisp, V. W., \& Eaton, K. L. (1999). Family expressiveness: A retrospective and new directions for research. In P. Philippot, R. S. Feldman, \& E. Coats (Eds.), The social context of nonverbal behavior (pp. 109-155). New York: Cambridge University Press.

Halberstadt, A. G., \& Eaton, K. L. (in press). A meta-analysis of family expressiveness and children's emotion expressiveness and understanding. Marriage and Family Review.

Hardy, D. F., Power, T. G., \& Jaedicke, S. (1993). Examining the relation of parenting to children's coping with everyday stress. Child Development, 64, 1829-1841.

Hoffman, M. L. (1983). Affective and cognitive processes in moral internalization. In E. T. Higgins, D. N. Ruble, \& W. W. Hartup (Eds.), Social cognition and social development: A sociocultural perspective (pp. 236-274). New York: Cambridge University Press.

Hoffman, M. L. (2000). Empathy and moral development: Implications for caring and justice. Cambridge, England: Cambridge University Press.

Huey, S. J., Jr., \& Weisz, J. R. (1997). Ego control, ego resiliency, and the five-factor model as predictors of behavioral and emotional problems in clinic-referred children and adolescents. Journal of Abnormal Psychology, 106, 404-415.

Isley, S. L., O'Neil, R., Clatfelter, D., \& Parke, R. D. (1999). Parent and child expressed affect and children's social competence: Modeling direct and indirect pathways. Developmental Psychology, 35, 547-560.

Kenny, D. A., \& Kashy, D. A. (1992). Analysis of the multitraitmultimethod matrix by confirmatory factor analysis. Psychological Bulletin, 112, 165-172.

Kliewer, W., Fearnow, M. D., \& Miller, P. A. (1996). Coping socialization in middle childhood: Tests of maternal and paternal influences. Child Development, 67, 2339-2357.

Kochanska, G., Murray, K., \& Coy, K. C. (1997). Inhibitory control as a contributor to conscience in childhood: From toddler to early school age. Child Development, 68, 263-277.

Kopp, C. B. (1982). Antecedents of self-regulation: A developmental perspective. Developmental Psychology, 18, 199-214.

Lengua, L. J., West, S. G., \& Sandler, I. N. (1998). Temperament as a predictor of symptomatology in children: Addressing contamination of measures. Child Development, 69, 164-181.

Lindahl, K. M. (1998). Family process variables and children's disruptive behavior problems. Journal of Family Psychology, 12, 420-436.

MacKinnon, D. P. (1994). Analysis of mediating variables in prevention and intervention research. In A. Cazares \& L. A. Beatty (Eds.), Scientific methods for prevention intervention research. NIDA Research Monograph 139 (pp. 127-153; DHHS Publication No. 94-3631). Washington, DC: U. S. Government Printing Office.

MacKinnon, D. P., Lockwood, C. M., Hoffman, J. M., West, S. G., \&
Sheets, V. (2002). A comparison of methods to test mediation and other intervening variables. Psychological Methods, 7, 83-104.

MacKinnon-Lewis, C., \& Lofquist, A. (1996). Antecedents and consequences of boys' depression and aggression: Family and school linkages. Journal of Family Psychology, 10, 490-500.

Matthews, K. A., Woodall, K. L., Kenyon, K., \& Jacob, T. (1996). Negative family environment as a predictor of boys' future status on measures of hostile attitudes, interview behavior, and anger expression. Health Psychology, 15, 30-37.

Messer, S. C., \& Gross, A. M. (1995). Childhood depression and family interaction: A naturalistic observational study. Journal of Clinical Child Psychology, 24, 77-88.

Mischel, W., Shoda, Y., \& Rodriguez, M. L. (1989). Delay of gratification in children. Science, 244, 933-938.

Murphy, B. C., Eisenberg, N., Fabes, R. A., Shepard, S., \& Guthrie, I. K. (1999). Consistency and change in children's emotionality and regulation: A longitudinal study. Merrill-Palmer Quarterly, 45, 413-444.

Muthen, L. K., \& Muthen, B. O. (1998). Mplus user's guide. Los Angeles, CA: Muthen \& Muthen.

Parke, R. D., \& Buriel, R. (1998). Socialization in the family: Ethnic and ecological perspectives. In W. Damon (Series Ed.) \& N. Eisenberg (Vol. Ed.), Handbook of child psychology: Vol. 3. Social, emotional, and personality development (5th ed., pp. 463-552). New York: Wiley.

Parpal, M., \& Maccoby, E. E. (1985). Maternal responsiveness and subsequent child compliance. Child Development, 56, 326-334.

Pulkkinen, L. (1986). The role of impulse control in the development of antisocial and prosocial behavior. In D. Olweus, J. Block, \& M. RadkeYarrow (Eds.), Development of antisocial and prosocial behavior: Research, theories, and issues (pp. 149-175). New York: Academic Press.

Rothbart, M. K., Ahadi, S. A., \& Hershey, K. L. (1994). Temperament and social behavior in childhood. Merrill-Palmer Quarterly, 40, 21-39.

Rothbart, M. K., Ahadi, S. A., Hershey, K., \& Fisher, P. (2001). Investigations of temperament at three to seven years: The Children's Behavior Questionnaire. Child Development, 72, 1394-1408.

Rothbart, M. K., \& Bates, J. E. (1998). Temperament. In W. Damon (Series Ed.) \& N. Eisenberg (Vol. Ed.), Handbook of child psychology: Vol. 3. Social, emotional, and personality development (5th ed., pp. 105-176). New York: Wiley.

Rothbaum, F., \& Weisz, J. R. (1994). Parental caregiving and child externalizing behavior in nonclinical samples: A meta-analysis. Psychological Bulletin, 116, 55-74.

Rubin, K. H., Hastings, P., Chen, X., Stewart, S., \& McNichol, K. (1998). Intrapersonal and maternal correlates of aggression, conflict, and externalizing problems in toddlers. Child Development, 69, 1614-1629.

Saarni, C. (1990). Emotional competence: How emotions and relationships become integrated. In R. A. Thompson (Ed.), Socioemotional development (pp. 115-182). Lincoln: University of Nebraska Press.

Sanson, A., Prior, M., \& Kyrios, M. (1990). Contamination of measures in temperament research. Merrill-Palmer Quarterly, 36, 179-192.

Scaramella, L. V., Conger, R. D., \& Simons, R. L. (1999). Parental protective influences and gender-specific increases in adolescent internalizing and externalizing problems. Journal of Research on Adolescence, 9, 111-141.

Skinner, E. A., \& Wellborn, J. G. (1994). Coping during childhood and adolescence: A motivational perspective. In R. Lemer, D. Featherman, \& M. Perlmutter (Eds.), Life-span development and behavior (Vol. 12, pp. 91-133). Hillsdale, NJ: Erlbaum.

Smith, M. (2001). Social and emotional competencies: Contributions to young African-American children's peer acceptance. Early Education and Development, 12, 49-72.

Smith, M., \& Walden, T. (2001). An exploration of African American preschool-aged children's behavioral regulation in emotionally arousing situations. Child Study Journal, 31, 13-45.

Spinrad, T. L., Losoya, S. H., Eisenberg, N., Fabes, R. A., Shepard, S. A., 
Cumberland, A., Guthrie, I. K., \& Murphy, B. (1999). The relations of parental affect and encouragement to children's moral emotions and behaviour. Journal of Moral Education, 28, 323-337.

Stanger, C., \& Lewis, M. (1993). Agreement among parents, teachers, and children on internalizing and externalizing behavior problems. Journal of Clinical Child Psychology, 22, 107-115.

Tabachnick, B. G., \& Fidell, L. S. (1996). Using multivariate statistics. New York: HarperCollins.

Teti, L. O., \& Cole, P. M. (1995, April). Emotion regulation in the preschool years: Relations to socialization and psychopathology. Paper presented at the meeting of the Society for Research in Child Development, Indianapolis, IN

Thompson, R. A. (1994). Emotion regulation: A theme in search of definition. In N. A. Fox (Ed.), The development of emotion regulation: Biological and behavioral considerations. Monographs of the Society for Research in Child Development, 59 (2-3, Serial No. 240), 25-52.

Thomson, E., \& Williams, R. (1984). A note on correlated measurement error in wife-husband data. Journal of Marriage and the Family, 46, 643-649.

Walden, T. A., \& Smith, M. C. (1997). Emotion regulation. Motivation and Emotion, 21, 7-25.

Williams, B. R., Ponesse, J. S., Schachar, R. J., Logan, G. D., \& Tannock, R. (1999). Development of inhibitory control across the life span. Developmental Psychology, 35, 205-213.

Winer, B. J. (1971). Statistical principles in experimental design. New York: McGraw-Hill.

Zahn-Waxler, C., Schmitz, S., Fulker, D., Robinson, J., \& Emde, R. (1996). Behavior problems in 5-year-old monozygotic and dizygotic twins: Genetic and environmental influences, patterns of regulation, and internalization of control. Development and Psychopathology, 8, 103-122.

Received September 17, 2001

Revision received July 22, 2002

Accepted July 22, 2002

\section{E-Mail Notification of Your Latest Issue Online!}

Would you like to know when the next issue of your favorite APA journal will be available online? This service is now available to you. Sign up at http://watson.apa.org/ notify/and you will be notified by e-mail when issues of interest to you become available! 